\title{
Efeito do armazenamento na energia corporal de juvenis do segundo estádio de Meloidogyne incognita infestados por Pasteuria penetrans*
}

\author{
Fernando da Silva Rocha', ${ }^{1,2}$ Vicente Paulo Campos$^{2}$, Renata da Silva Canuto ${ }^{2}$, Ricardo Magela de Souza ${ }^{2}$
}

*Parte da Tese de Doutorado do primeiro autor, apresentada à Universidade Federal de Lavras/UFLA, para a obtenção do título de Doutor. ${ }^{1}$ Bols ista do CNPq; ${ }^{2}$ Departamento de Fitopatologia, Universidade Federal de Lavras, CP 3037, CEP. 37200-000, Lavras, MG, Brasil. e-mail: rochafsplant@yahoo.com.br

Autor para corres pondência: Fernando da Silva Rocha rochafsplant@yahoo.com.br

Data de chegada: 10/07/2007. Aceito para publicação em: 23/04/2008.

\section{RESUMO}

Rocha, F. S.; Campos, V. P.; Canuto, R. S.; Souza, R. M. Efeito do armazenamento na energia corporal de juvenis do segundo estádio de Meloidogyne incognita infestados por Pasteuria penetrans. Summa Phytopathologica, v.35, n.1, p.15-19, 2009

Neste trabalho, objetivou-se estudar o efeito do período de armazenamento no teor de lipídios de juvenis do segundo estádio (J2) de $M$. incognita com endósporos de $P$. penetrans na infectividade e reprodução em tomateiro. Suspensões de $M$. incognita contendo ou não endósporos de $P$. penetrans aderidos àcutícula foram armazenadas por $0,3,6,9$ e 12 dias, a $28^{\circ} \mathrm{C}$. Após cada período de estocagem, determinou-se a concentração de lipídios neutros corporais por meio da análise de imagem dos $\mathrm{J} 2$ coloridos com o corante "Oil Red O". Em seguida, $1.000 \mathrm{~J} 2$ foram inoculados em mudas de tomateiros. Após 28 dias, avaliou-se o número de fêmeas parasitadas, número de endósporos/fêmea, número de galhas, massas de ovos e de ovos/ $\mathrm{g}$ de raiz. O teor de lipídio dos $\mathrm{J} 2$ reduziu-se com o aumento do período de estocagem. Porém, maiores perdas ocorreram nos J2 sem endósporos de P. penetrans. A proporção entre as perdas dos
J2 com e sem $P$. penetrans foi pequena e decrescente com o período de estocagem. Entretanto, a desproporção foi grande entre 3 e 6 dias de armazenamento dos $\mathrm{J} 2$ com e sem $P$. penetrans com relação aos parâmetros reprod ução e número de galhas, indicando consumo de fontes alternativas ao lipídio neutro de energia pelo J2 parasitado. Mas o período de armazenamento sempre reduziu a reprodução e número de galhas formadas em tomateiros por $\mathbf{J} 2$ com e sem $P$. penetrans. A perda dess as fontes de energia, ao que tudo indica, leva muitos $\mathrm{J} 2$ a morrer antes de chegar ao estádio adulto, pois o número de fêmeas parasitadas reduz-se com o armazenamento, além de propiciar menor produção de endósporos por fêmea. O J2 parasitado por $P$. penetrans necessita encontrar rapidamente a raiz e não permanecer no solo por mais de 6 dias antes de parasitar a planta.

Palavras-chave adicionais: Pasteuria penetrans, controle biológico, lipídios neutros, Meloidogyne incognita.

\section{ABSTRACT}

Rocha, F. S.; Campos, V. P.; Canuto, R. S.; Souza, R. M. Effect of storage on body energy of second stage juveniles of Meloidogyne incognita infested by Pasteuria penetrans. Sum ma Phytopathologica, v.35, n.1, p.15-19, 2009

This work aimed to study the effect of storage period on lipid content of second stage juveniles (J2) of $M$. incognita with endospores of $P$. penetrans on infectivity and reproduction in tomato. Suspensions of $M$. incognita containing or not endospores of $P$. penetrans adhered to cuticle were stored by $0,3,6,9$ and 12 days at $28^{\circ} \mathrm{C}$. After each storage period, the concentration of neutral lipids in the body of $\mathrm{J} 2$ was determined by image analysis of $\mathrm{J} 2$ stained with "Oil Red O". After that, $1.000 \mathrm{~J} 2$ were inoculated in tomato seedlings. After 28 days, the number of infected females, number of endospores per females, number of galls, number of egg masses and number of eggs per gram of root were evaluated. The lipid content of J2 reduced with the increase of storage period. However, greater lost occurred on $\mathrm{J} 2$ without endospores of $P$. penetrans. The ratio between $\mathrm{J} 2$ lipid losses with and without $P$. penetrans was small and decreased with storage period. However, the ratio between $\mathrm{J} 2$ with and without $P$. penetrans was greatest between 3 and 6 days of storage in relation to parameters reproduction and number of galls, indicating consumption of alternative energy sources others than neutral lipids by infected J2. But the storage period always reduced the reproduction and number of galls formed in tomatoes by $\mathrm{J} 2$ with and without $P$. penetrans. The loss of those energy sources indicate that many $\mathrm{J} 2$ dye before adult stage, because the number of parasitized females reduced with storage, besides of smaller endospores production per female. The $\mathrm{J} 2$ infested by $P$. penetrans needs to find the root quickly and should not stay in the soil for more than 6 days before parasitizing the plant.

Keywords: sbiological control, neutral lipids, Meloidogyne incognita.

Pasteuria penetrans (Thorne) Sayre \& Starr é uma bac téria grampositiva formadora de endósporos imóveis e parasita obrigatória de diversas espécies de fitonematóides $(3,11,16,22,23)$. O seu potencial como agente para o controle biológico tem merecido maior atenção para as espécies do gênero Meloidogyne $(9,21,24)$. O ciclo de vida de P. penetrans em Meloidogyne spp. consiste na adesão, germinação dos endósporos e na infecção ocorrida no interior do nematóide vivo. A adesão ocorre quando o nematóide movimenta-se no solo e entra em 
contato com o endósporo, representando, portanto, uma etapa importante no início do parasitismo. A natureza química da cutícula do juvenil do segundo estádio (J2) é de grande importância para que ocorra a adesão dos endósporos de $P$. penetrans em Meloidogyne spp. Assim, alterações na cutícula ou mesmo a morte do nematóide podem afetar o processo de adesão. No solo, a adesão pode sofrer a influência de vários fatores bióticos e abióticos (2, 5, 6, 14, 15, 16, 18, 25, 26).

A aderência do endósporo ao J2 de Meloidogyne spp. constitui o iníc io do ciclo de vida da bactéria, além de propiciar a continuação do ciclo através de gerações do nematóide. Por isso, a eficiência de multiplicação e o controle de Meloidogyne por P. penetrans estão associados a grandes populações de $\mathrm{J} 2$ com endósporos aderidos à cutícula em plantas hospedeiras ao nematóide $(12,20,28,29)$. No entanto, altas quantidades de endósporos aderidos reduzem a mobilidade e a penetração do $\mathrm{J} 2$ na raiz $(5,7,13)$ e, por conseguinte, aumentam sua permanência no solo, podendo interromper o ciclo de vida da bactéria.

Após a eclosão, o J2 de Meloidogyne spp. possui reservas energéticas corporais, principalmente na forma lipídica, necessárias para locomoção e infectividade $(10,31)$. Contudo, no solo, o J2 nem sempre encontra de imediato a raiz nova para o processo de infec ção, aguardando a sua formação a partir de raízes mais velhas ou tendo de movimentar-se para encontrá-la. O período em que o J2 permanece no solo, com ou sem endósporos aderidos ao seu corpo aindanão foi bem estudado, principalmente com relação à perda da reserva lipídica corporal, infectividade e reprodução no hospedeiro após algum período à es pera ou procura do hospedeiro. Desta forma, objetivou-se, neste trabalho, estudar o efeito do período de armazenamento no teor de lipídios de $\mathrm{J} 2$ de Meloidogyne incognita com endósporos de $P$. penetrans, na infectividade e reprodução do $\mathrm{J} 2$ infectado em tomateiro.

\section{MATERIALE MÉTODOS}

Preparo das soluções tampões de fosfato de sódio: Foram preparadas soluções estoques $\mathrm{A}$ e $\mathrm{B}$ de $\mathrm{Na}_{2} \mathrm{HPO}_{4}$ e $\mathrm{NaH}_{2} \mathrm{PO}_{4} 0,2 \mathrm{M}$, respectivamente. A seguir, adicionaram-se $175 \mathrm{~mL}$ da solução $\mathrm{A}, 75$ $\mathrm{mL}$ da solução $\mathrm{B}$, completando-se o volume final para um litro com água destilada. Ajustes em pHmetro foram feitos para obtenção da solução tampão na concentração de $0,05 \mathrm{M}$ e pH 7,0. Esta solução tampão foi usada para promover uma melhor adesão dos endósporos de $P$. penetrans à cutícula do nematóide.

Obtenção de mudas de tomateiro: Sementes de tomateiro, cv. Kada, do grupo Santa Cruz, foram semeadas em bandejas contendo substrato Plantmax e mantidas em casa-de-vegetação. Mudas saudáveis e de tamanho ideal para o trans plantio e instalação dos ensaios foram obtidas 40 dias após a semeadura.

Obtenção dos endósporos de Pasteuria penetrans: Os endósporos de $P$. penetrans, is olado $\mathrm{PP}_{12}$ originário do município de Ijaci, MG, foram multiplicados em raízes de tomateiros cultivados em vasos ou bandejas mantidos em casa-de-vegetação. As raízes de tomateiro foram separadas do substrato, lavadas em água, cortadas em pedaços de, aproximadamente, 2 centímetros e embebidas por $24 \mathrm{~h} \mathrm{em}$ solução enzimática composta de 4,0 mL de pectinase-SIGMA (P9179) e 4,0 g de cellulase-SIGMA (C-1184). A seguir, as raízes foram trituradas em liquidific ador por 40 segundos e vertidas em peneira de $0,84 \mathrm{~mm}$ sobre peneira de $0,025 \mathrm{~mm}$, coletando-se o material retido nessa última peneira em Erlenmeyer de 2 litros. As fêmeas de $M$. incognita contidas nesse material foram retiradas com o auxílio de um estilete de ponta recurvada e colocadas em tubo de ensaio contendo solução tampão de fosfato de sódio $0,05 \mathrm{M} \mathrm{e} \mathrm{pH} \mathrm{7,0.} \mathrm{Essas} \mathrm{fêmeas}$ parasitadas por $P$. penetrans foram esmagadas em $2 \mathrm{~mL}$ de água destilada, em triturador de tecidos (Pyrex 7727-15) previamente lavado com leite desnatado e enxaguado com água destilada. Esse procedimento foi realizado para todos os recipientes em contato com os endósporos. Essa suspensão de $P$. penetrans foi passada por peneira de $0,028 \mathrm{~mm}$ para retirada de restos de fêmeas e/ou ovos, obtendo-se uma sus pensão límpida de endósporos quantificada através de câmara de Newbauer e armazenada a $8^{\circ} \mathrm{C}$ em câmara fria. Essa suspensão foi pré-tratada em sonificador durante $20 \mathrm{~min}$, antes do teste de adesão.

Obtenção de juvenis do segundo estádio (J2) de Meloidogyne incog nita: Raízes de to mateiros (L. esculentum cv. Kada) cultivados em casa-de-vegetação e infestados com $M$. incognita, foram lavadas cuidadosamente e cortadas em pedaços de, aproximadamente, um centímetro. Os ovos foram obtidos conforme técnica de Hussey \& Barker (8). Ao final, o material retido na peneira de $0,025 \mathrm{~mm}$ foi recolhido com o auxílio de jatos de sacarose $(0,5 \mathrm{~g} / \mathrm{mL})$, em tubos de plástico de $50 \mathrm{~mL}$. Em seguida, adicionaram-se, aproximadamente, $3 \mathrm{~g}$ de caulim nesses tubos, que foram agitados para colocar em suspensão todo o precipitado e, a seguir, centrifugados por $60 \mathrm{~s}$ a $680 \mathrm{~g}$. Transcorrido esse tempo, transferiu-se o sobrenad ante numa peneira de $0,025 \mathrm{~mm}$, sem agitar o precipitado. Recolheram-se os ovos retidos na peneira em béquer de $200 \mathrm{~mL}$, utilizando-se pisseta contendo água destilada. Em câmara de fluxo laminar, toda a suspensão foilavada por quatro vezes em água destilada e esterilizada, utilizando-se peneira desinfestada de 0,025 mm e, então, colocada em béquer de vidro esterilizado. Para a obtenção dos J2, utilizou-se câmara de eclosão formada com tela e papel celulose de lenços duplos de 14,8 x 21,5 cm $\left(\right.$ Klein $\left.^{\circledR}\right)$, montada em funil de vidro. Foram utilizados no ensaio apenas os $\mathrm{J} 2$ obtidos no terceiro dia.

Instalação e avaliação do ensaio: Os J2 de M. incognita foram vertidos em peneira de $11 \mathrm{~mm}$ e recolhidos através de pisseta contendo soluções tampão de fosfato de sódio $0,05 \mathrm{M} \mathrm{e} \mathrm{pH} \mathrm{7,0} \mathrm{em} \mathrm{frascos}$ Erlenmeyer. Aseguir, foram quantificados em microscópio de objetivas invertidas e separados em duas porções. Em uma delas, ad icionaramse $4 \mathrm{~mL}$ de suspensão de endósporos de $P$. penetrans na concentração de $4,2 \times 10^{6}$ endósporos $/ \mathrm{mL}$, completando-se o volume final do frasco para $20 \mathrm{~mL}$ com solução tampão. Na outra porção, adicionou-se apenas solução tampão, elevando-se a suspensão ao mesmo volume final da porção anterior. Em seguida, os frascos foram acoplados a uma mangueira plástica ligada a uma bomba de aquário para borbulhamento constante, por 24 horas. Ao final desse tempo, o conteúdo de cada fras co foi passado em peneira de $0,025 \mathrm{~mm}$ e lavado em água corrente para a retirada dos endósporos não aderidos à cutícula do $\mathrm{J} 2$, sendo recolhidos novamente para os frascos de Erlenmeyer. Para a quantificação dos endósporos aderidos, os $\mathbf{J} 2$, em número de 20 , escolhidos ao acaso, por frasco, foram observados em microscópio de objetivas invertidas, com aumento de $250 \mathrm{X}$, contando-se o número de endósporos aderidos por $\mathrm{J} 2$ e o número de $\mathrm{J} 2$ com endósporos aderidos para o cálculo de percentagem de adesão. Desta forma, verificou-se que $96 \%$ dos $\mathrm{J} 2$ tinham, em média, 10 end ósporos aderidos à cutícula. De cada frasco, pipetaram-se $2 \mathrm{~mL}$ de suspensão para determinar a concentração de lipídios neutros no corpo do J2 antes do armazenamento por meio de análise de imagem $(1,4,30)$. Para isto, a suspensão contendo os $\mathrm{J} 2$ foi concentrada em $0,5 \mathrm{~mL}$ e ad icionaramse $3 \mathrm{~mL}$ da solução corante "Oil Red O", seguido de aquecimento em banho-maria, a $60^{\circ} \mathrm{C}$, por 20 minutos. Após o resfriamento em temperatura ambiente, os $\mathrm{J} 2$ de $M$. incognita foram concentrados novamente em $0,5 \mathrm{~mL}$ da solução corante e adicionaram-se $3 \mathrm{~mL}$ de glic erina 50\%. Em seguida, montaram-se lâminas contendo $20 \mathrm{~J} 2$ de M. incognita e a partir das fotografias dos $\mathrm{J} 2$, utilizou-se o programa 
"Image Tool for Windows", para estimar a área total do corpo do J2 e aquela de coloração vermelha correspondente aos lipídios. Desta forma, a partir da área de coloração vermelha, obteve-se o percentual de lipídios neutros em relação à área total do corpo dos J2 de $M$. incognita.

As suspensões foram calibradas em $1.000 \mathrm{~J} 2 \mathrm{com}$ ou sem endósporos $/ \mathrm{mL}$ e armazenadas em estufa incubadora(B.O.D.), a $28^{\circ} \mathrm{C}$, por 3, 6, 9 e 12 dias em água parada. Nesse momento, os J2 recentemente eclodidos foram inoculados em tomateiro servido de testemunha. De cada período de armazenamento, obtiveram-se $2 \mathrm{~mL}$ da suspensão e, nos J2, fez-se a coloração de lipídios neutros após o armazenamento com o corante "Oil Red O", já descrito, e estimou-se o percentual médio de lipídios neutros do corpo do J2, obtendo-se, assim, o valor de lipídio no momento da inoculação em cada período de inoculação. A seguir, $1.000 \mathrm{~J} 2$ de $M$. incognita, contendo ou não endósporos de $P$. penetrans aderidos, foram inoculados em mudas de tomateiro plantadas em copos plásticos de $300 \mathrm{~mL}$ de volume, com substrato formado de solo e areia, na proporção 1:1. Para a inoculação, os $\mathrm{J} 2$ foram dispersos em $4 \mathrm{~mL}$ de água e dis persados em 4 furos de \pm $3 \mathrm{~cm}$ de profundidade ao redor das mudas. Os copos foram colocados em sala climatizada com temperatura de $27 \pm 2^{\circ} \mathrm{C}$, fotoperíodo de 14 $\mathrm{h}$ de luz e mantidos nessas condições durante 28 dias. Ao final desse tempo, cortou-se a parte aérea dos tomateiros e retirou-se o sis tema radicular do solo em água parada. Para a quantific ação do número de fêmeas parasitadas e do número de endósporos/fêmea, 80 delas, escolhidas ao acaso, foram retiradas com estilete de ponta fina. Quarenta delas foram esmagadas em lâminas de vidro contendo água destilada, sob lamínula, contando-se em microscópio de objetivas invertidas, aumento de 500X, o número de fêmeas parasitadas e consideraram-se parasitadas todas aquelas com endósporos encontrados no seu interior. As demais 40 fêmeas de cada tratamento foram esmagadas em lâminas escavadas contendo $1 \mathrm{~mL}$ de água destilada e, em seguida, essa suspensão foi transferida para uma câmara de Newbauer para a quantificação do número de endósporos/fêmea. A seguir, as massas de ovos dos nematóides nos sistemas radiculares foram coloridas de vermelho em solução contendo corante artificial empregado na fabricação de sucos, conforme técnica de Rocha et al. (19). Após a coloração, as raízes foram deixadas sobre papel-toalha por 10 minutos, possibilitando, assim, a avaliação do peso da matéria fresca das raízes, seguida da contagem do número de massas de ovos e de galhas por sistema radicular. Para a quantific ação do número de ovos por sistema radicular, as raízes foram cortadas em pedaços de, aproximadamente,

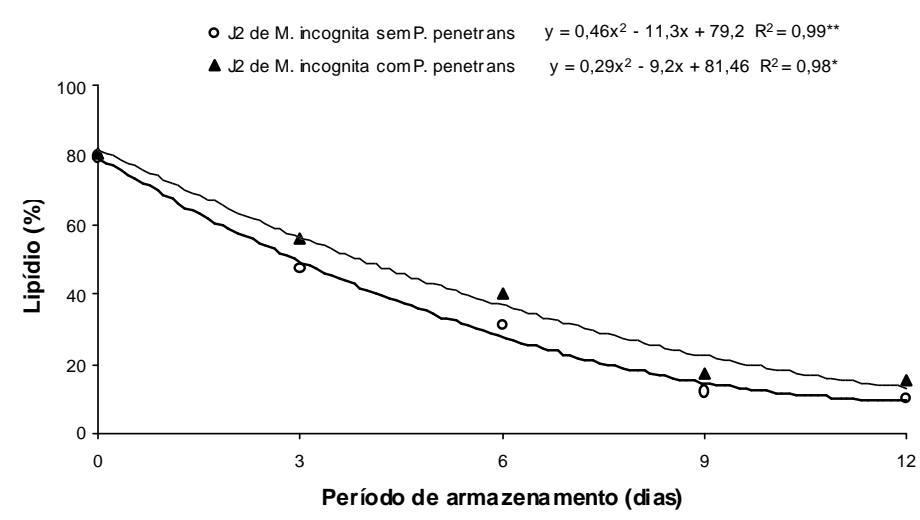

Figura 1. Percentagem de lipídios neutros de juvenis do segundo estádio (J2) de Meloidogyne incognita, contendo ou não endósporos de Pasteuria penetrans, aderidos à cutícula e armazenados em água parada, a $28^{\circ} \mathrm{C}$, por diferentes períodos.
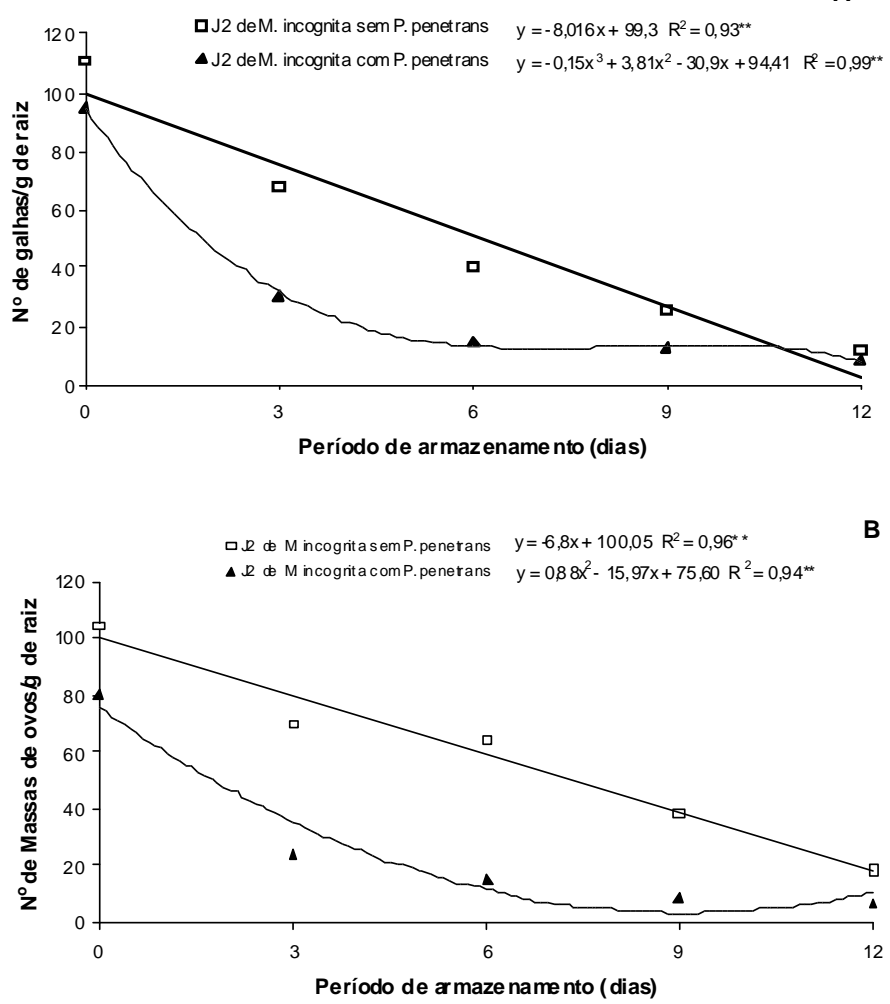

C

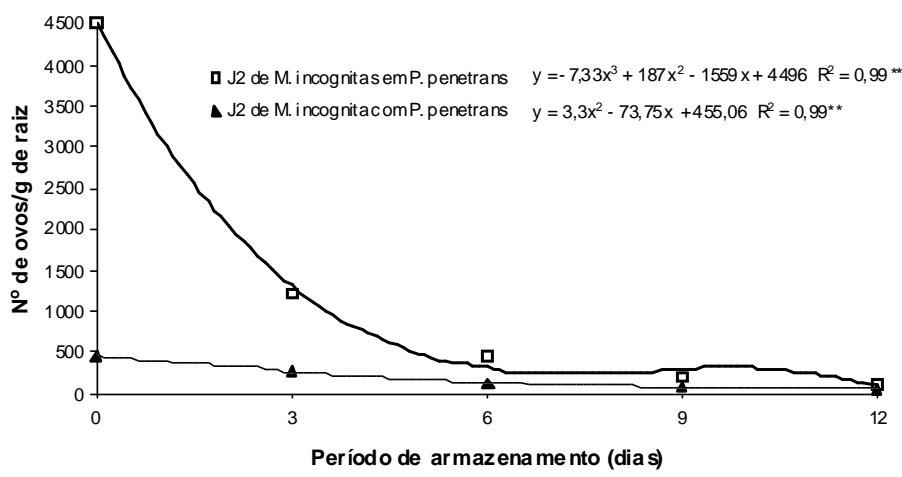

Figura 2. Efeito do período de armazenamento em água parada, a $28^{\circ} \mathrm{C}$, de juvenis do segundo estádio de Meloidogyne incognita, contendo ou não endósporos de Pasteuria penetrans, na infectividade e na reprodução do nematóide. A) número de galhas/g de raiz de tomateiro, B) número de massas de ovos/g de raiz de tomateiro, C) número de ovos/g de raiz de tomateiro.

$2 \mathrm{~cm}$ de comprimento e os ovos obtidos pela técnica de Hussey \& Barker (8). Em microscópio de objetivas invertidas, quantificou-se o número de ovos de $M$. incognita por sistema radicular.

Utilizou-se o delineamento inteiramente casualizado, com 6 repetições. Os dados obtidos foram transformados em $\sqrt{x+0.5}$ para análise de variância e as médias comparadas pelo teste de Tukey a $5 \%$ de probabilidade. As análises de variância foram realizadas pelo programa estatístico $S$ is var e as variáveis significativas, pelo teste $\mathrm{F}$, foram submetidas à análise de regressão para ajuste do melhor modelo. 


\section{RESULTADOS E DISCUSSÃO}

O teor lipídico dos $\mathrm{J} 2$ de $M$. incognita reduziu-se com o aumento do período de estocagem a $28^{\circ} \mathrm{C}$, apresentando maior perda lipídica aqueles $\mathrm{J} 2$ sem endósporo de $P$. penetrans aderidos à cutícula (Figura 1). A taxa de perda de lipídios neutros dos $\mathrm{J} 2$ estocados sem endósporos aderidos foi de 40, 61 e $85 \%$ em relação ao ní vel original aos 3, 6 e 9 dias, respectivamente, enquanto naqueles contendo endós poros de $P$. penetrans essa perda foi de 29, 49 e $79 \%$ nos mesmos períodos de estoc agem, cuja proporção entre eles foi pequena e decrescente $(1,38$; $1,24$ e 1,07$)$.

Os J2 de $M$. incognita com endósporos de P. penetrans aderidos ao corpo e imediatamente inoculados em tomateiros induziram a formação de galhas em quantidades semelhantes àqueles sem $P$. penetrans (Figura 2A). Entretanto, a produção de massa de ovos foi reduzida em $23 \%$ nos tomateiros infectados por $\mathrm{J} 2$ com endósporos, sendo ainda maior a qued a no número de ovos nas raízes do tomateiro infectados por $\mathrm{J} 2$ com endósporos de $P$. penetrans, chegando a $89 \%$ de redução (Figuras 2B e C).

Com o armazenamento e posterior inoculação em tomateiros de J2 come sem endósporos ocorreu redução no número de galhas, massas de ovos e ovos por grama de raiz, porém em intensidades diferentes entre eles. As maiores quedas no número de galhas e de massas de ovos de $M$. incognita resultantes da infecção de tomateiros por $\mathrm{J} 2$ com endósporos ocorreram entre os períodos de 3 e 6 dias de armazenamento, enquanto que na produção de ovos/g de raiz a maior queda foi nos primeiros 3 dias de armazenamento do $\mathrm{J} 2 \mathrm{com}$ endósporos. Apartir do 6o dia as diferenç as entre o número de galhas, mass as de ovos e ovos/g de raiz em tomateiros infectados por J2 com e sem endósporos diminuem e chegam a se igualarem no final do ensaio, porém em níveis bem baixos (Figuras $2 \mathrm{~A}, \mathrm{~B}$ e C), criando desproporção bem maior do que a observada na curva energética dos lipídios neutros (Figura 1). O parasitismo das fêmeas por P. penetrans e o número de endósporos produzidos por fêmea de $M$. incognita foram significativamente reduzidos com o armazenamento dos $\mathrm{J} 2$ infestados chegando a zero a partirde 9 dias de armazenamento (Tabela $1)$.

A maior preservação da reserva lipídica corporal do J2 com endósporo de $P$. penetrans, comparado com aquele sem endósporos (Figura 1), ao que tudo indica, está relacionada ao movimento mais lento dos J2 infestados comendósporos da bactéria. Stirling et al. (27) e Davies et al. (5) encontraram movimentação menor dos J2 contendo 7 endósporos de $P$. penetrans em relação àqueles não infestados. Embora ocorra a preservação da reserva lipídica pelos J2 infestados com endósporos, de acordo com os dados aqui apresentados, o armazenamento sempre reduziu mais a infectividade e a reprodução dos J2 parasitados, em relação aos não parasitados, em qualquer período de tempo (Figura 2). Desta forma, o J2 parasitado neces sita encontrar rapidamente a raiz e não permanecer no solo por mais de 6 dias. Campos (1) verificou perda de 38,82 e 56,12\% no lipídio corporal de J2 de M. javanica a partir do segundo e quarto dias de armazenamento dos $\mathrm{J} 2 \mathrm{em}$ água parada a $28^{\circ} \mathrm{C}$, o que refletiu em redução de $44,64 \%$ na produção de ovos e $73,68 \%$ no número de fêmeas, respectivamente. Van Gundy et al. (31) verificaram que o armazenamento de $\mathrm{J} 2$ de $M$. javanica, a $25^{\circ} \mathrm{C}$, por 4 dias, causou perda lipídica de $41,33 \%$, porém não afetou a mobilidade dos $\mathbf{J} 2$.

Dois patossistemas estão envolvidos nesses ensaios, isto é, $M$. incognita-tomateiro e $P$. penetrans-M. incognita, alémde três processos competidores por energia de $M$. incognita como: armazenamento do $\mathrm{J} 2$ em água a temperatura de $28^{\circ} \mathrm{C}$, infectividade do $\mathrm{J} 2$ por $P$. penetrans
Tabela 1. Efeito do período de armazenamento de juvenis do segundo estádio de Meloidogyne incognita com endósporos de Pasteuria penetrans aderidos à cutícula no parasitismo e na produção de endósporos por fêmeas.

\begin{tabular}{lll}
\hline Tratamentos & Fêmeas parasitadas $(\%)$ & № de endósporos/ fêmea \\
\hline 0 dia & $80 \mathrm{a}$ & $4,68 \times 10^{5} \mathrm{a}$ \\
3 dias & $45 \mathrm{~b}$ & $3,0 \times 10^{3} \mathrm{~b}$ \\
6 dias & $12 \mathrm{~b}$ & $1,25 \times 10^{2} \mathrm{~b}$ \\
9 dias & $0 \mathrm{c}$ & $0 \mathrm{~b}$ \\
12 dias & $0 \mathrm{c}$ & $0 \mathrm{~b}$ \\
\hline $\mathbf{C V}(\boldsymbol{\%})$ & 12,34 & 40,80 \\
\hline
\end{tabular}

Médias seguidas por letras distintas, na coluna, diferem entre si pelo teste de Tukey a 5\% de probabilidade.

e reprodução da fêmea infectada. A reprodução em qualquer processo biológico constitui o maior dreno em energia. Nos fitonematóides de elevada produção de ovos como nos nematóides de galhas e do cisto as fêmeas morrem no final da postura. $\mathrm{O}$ armazenamento de $\mathrm{J} 2 \mathrm{em}$ temperaturas altas leva a redução do nível de lipídio corporal $(4,10$, 31). Entretanto, o terceiro processo chamado aqui de competidor de energia, qual seja a infectividade de $P$. penetrans em $M$. incognita, não compete por energia nos primeiros eventos do parasitismo do J2 pela bactéria como ocorre quando o $\mathrm{J} 2$ com endósporos é armazenado em água, pois, o teor de lipídio neutro é maior no J2 com endósporo comparado como J2 não infestado (Figura 1). Contudo, a redução no número de galhas em tomateiro pelo $\mathrm{J} 2$ infestado por $P$. penetrans e armazenado foi maior comparado com $\mathrm{J} 2$ não infestado e armazenado pelo mesmo período (Figura 2A). Desta forma, outras fontes alternativas de energia, além dos lipídios neutros, foram exauridas pelo $\mathrm{J} 2$ infestado por $P$. penetrans durante o armazenamento e, portanto, reduzindo a infectividade e reprodução dos $\mathrm{J} 2$ parasitados por $P$. penetrans em tomateiro (Figuras 2A, B e C). Lee \& Atkins on (10) e Qiu \& Bedding (17) relataram que os órgãos aparentemente sem lipídio podem obter energia por meio de outras fontes alternativas aos lipídios neutros como glicogênio e trealose. Van Gundy et al. (31) relataram o uso de lipídios neutros e proteínas como fontes de energia de J2 de $M$. javanica. A perda dessas fontes de energia, ao que tudo indica, leva muitos $\mathrm{J} 2$ a morrerem antes de chegar ao estádio adulto, pois o número de fêmeas parasitadas reduz-se com o armazenamento, além de propiciar a menor produção de endósporos (Tabela 1).

O cultivo "in vitro" de $P$. penetrans talvez poss a explicar o papel dessas substâncias no crescimento e reprodução dessa bactéria. Então, para maior sucesso do parasitismo e reprodução de P. penetrans em M. incognita, o $\mathrm{J} 2$ infestado precisa imediatamente parasitar a planta e o retardamento por 6 dias leva a morte do J2 parasitado.

\section{REFERÊNCIAS BIBLIOGRÁFICAS}

1. Campos, H. D. Aspectos do parasitismo e da privação alimentar do nematóide de galhas (Meloidogyne javanica) e do cisto (Heterodera glycines) em soja. 2003. 203f. Tese (Doutorado em Fitopatologia) - Universidade Federal de Lavras, Lavras.

2. Campos, V. P.; Souza, J. T. de; Souza, R. M. de. Controle de fitonematóides por meio de bactérias. Revisão Anual de Patologia de Plantas, Passo Fundo, v.6, p.285-327, 1998.

3. Chen, Z.X.; Dickson, D.W. Review of Pasteuria penetrans: Biology, Ecology, and Biological Control Potential. Journal of Nematology, Lawrence, v.30, p.313-340, 1998.

4. Christophers, A.E.P.; Patel, M.N.; Benson, J.A.; Saka, V.W.; Evans, A.A.F.; Wright, D.J. A rapid field-laboratory biossay to assess the infectivity of Meloidogyne spp. second stage juveniles. Nematologica, Leiden, v.43, n.1, p.117-120, 1997. 
5. Davies, K. G.; Laird, V. E.; Kerry, B. R. The mobility, development and infection of Meloidogyne incognita encumbered with spores of the obligate hyperparasite Pasteuria penetrans. Revue de Nématologie, Montrouge Cedex, v. 14, n. 4, p. 611-618, 1991.

6. Freitas, L.G.; Dickson, D.W.; Mitchell, D.J.; Hewlett, T.E. Infectivity and suppression of Pasteuria penetrans to Meloidogyne arenaria race 1 in tomato following soil fumigation. Nematologia Brasileira, Brasilia, v.24, n.2, p.157-166, 2000.

7. Gomes, C. B.; Freitas, L.G.; Ferraz, S.; Oliveira, R.D.L.; Osório, V.A. Efeito do número de endósporos de Pasteuria penetrans e do método de promoção da adesão sobre a penetração de Meloidogyne javanica e produção da bactéria em tomateiro. Nematologia Brasileira, Brasília, v.26, n.2, p.119-130, 2002.

8. Hussey, R. S.; Barker, K.R. A comparison of methods for colecting inocula of Meloidogyne spp including a new technique. Plant Disease Repórter, St. Paul, v.57, n.12, p.1025-1028, 1973.

9. Jalata, P. Biological control of plant-parasitic nematodes. Annual Review of Phytopathology, Palo Alto, v.24, p.453-489, 1986.

10. Lee, D.L.; Atkinson, H.J. Physiology of nematodes. New York: Columbia University Press, 1977. 215p.

11. Mankau, R. Bacillus pentrans n. comb. Causing a virulent disease of plant parasitic nematodes. Journal of Invertebrate Pathology, San Diego, v.26, n.3, p.333-339, 1975.

12. Mankau, R. Biological control of nematodes pests by natural enemies. Annual Review of Phytopathology, Palo Alto, v.18, p.415-440, 1980.

13. Mateille, T.; Duponnis, R.; Dabiré, K.; N'Diayes, S.; Diop, M.T. Influence of abiotic soil factors and the host plant on the infection of phytoparasitic nematodes of the genus Meloidogyne by Pasteuria penetrans. Europeen Journal Soil Biology, Paris, v.32, n.2, p.81-83, 1996.

14. Mateille, T.; Duponnois, R.; Dabiré, K.; N'Diayes, S.; Diop, M. T. Influence of the soil on the transport of the spores of Pasteuria penetrans, parasite of nematodes of the genus Meloidogyne. European Journal of Soil Biology, Paris, v. 32, n. 2, p. 81-88. 1996.

15. Maximiniano, C.; Campos, V.P.; Souza, R.M. de.; Almeida, A.R. de. Efeito do $\mathrm{pH}$ e filtrados bacterianos na adesão de endósporos de Pasteuria penetrans. Nematologia Brasileira, Brasília, v.25, n.1, p.21-26, 2001 .

16. Oostendorp, M.; Dickson, D. W.; Mitchell, D. J. Host range and ecology of isolates of Pasteuria spp. from the southeastern United States. Journal of Nematology, Lakeland, v. 22, n. 4, p. 525-531. 1990.

17. Qiu, L.; Bedding, R. A. Energy metabolism and survival of the infective juveniles of Steinernema carpocapsae under ogygen- deficient conditions. Journal of Nematology, Lakeland, v. 32, n. 3, p. 271-280, 2000.

18. Rocha, F.S.; Campos, V.P. Efeito de filtrados fúngicos na adesão de endósporos de Pasteuria penetrans e na infectividade e parasitismo de juvenis de segundo estádio de Meloidogyne incognita. Nematologia Brasileira, Brasília, v.24, n.2, p.239-244, 2000.

19. Rocha, F.S.; Muniz, M.F.S.; Campos, V. P. Coloração de fitonematóides com corantes usados na indústria alimentícia brasileira. Nematologia Brasileira, Brasília, v.29, n.2, p.293-297, 2005.

20. Sharma, R.D.; Stirling, G.R. In vivo mass production systems for Pasteuria penetrans. Nematologica, Leiden, v.37, p.483-485, 1991.

21. Souza, J. T. de; Campos, V. P. Efeito do isolado P1-UFLA de Pasteuria penetrans sobre a primeira geração de Meloidogyne javanica (Treub) Chitwood. Nematologia Brasileira, Brasília, v. 21, n. 2, p. 93-102, 1997.

22. Souza, J.T. de.; Souza, R.M.; Campos, V.P. Ocorrência e flutuação populacional de Pasteuria spp. em Minas Gerais. Nematologia Brasileira, Brasília, v.20, n.2, p.41-51, 1996.

23. Spaull, V.W. Observations on Bacillus penetrans infecting Meloidogyne in sugarcane fields in South Africa. Revue de Nématologie, Montrouge Cedex, v.7, n.3, p.277-282, 1984.

24. Stirling, G. R. Biological control of Meloidogyne javanica with Bacillus penetrans. Phytopathology, St. Paul, v. 74, n. 1, p. 5560, 1984.

25. Stirling, G. R. Biological control of plant-parasitic nematodes: progress, problems and prospects. Melksham: Redwood Press, 1991. 282 p.

26. Stirling, G.R. Effect of temperature on infection of Meloidogyne javanica by Bacillus penetrans. Nematologica, Leiden, v.27, n.4, p.458-462, 1981

27. Stirling, G.R.; Sharma, R.D.; Perry, J. Attachment of Pasteuria penetrans to the root-knot nematode Meloidogyne javanica in soil and its effects on infectivity. Nematologica, Leiden, v.36, p.246-252, 1990.

28. Stirling, G.R.; Wachtel, M.F. Mass production of Bacillus penetrans for the biological control of root-knot nematode Meloidogyne javanica in soil and its effect on infectivity. Nematologica, Leiden, v.26, n.3, p.308-312, 1980.

29. Stirling, G.R.; White, A. M. Distribution of a parasite of rootknot nematodes in South Australia vineyards. Plant Disease, v.66, n.1, p.52-53, 1982.

30. Storey, R.M.J. The initial neutral lipid reserves of juveniles of Globodera spp. Nematologica, Leiden, v.29, p.144-150, 1983.

31. Van Gundy, S. D.; Bird, A. F.; Wallace, H. R. Aging and starvation in juveniles of Meloidogyne javanica and Tylenchulus semipenetras. Phytopathology, St. Paul, v.57, p.559-571, 1967. 